\title{
Pemberdayaan Masyarakat Mengenai Kepatuhan Diet dan Pengobatan Hipertensi
}

\author{
Community Empowerment Regarding Diet Compliance and Hypertension Treatment
}

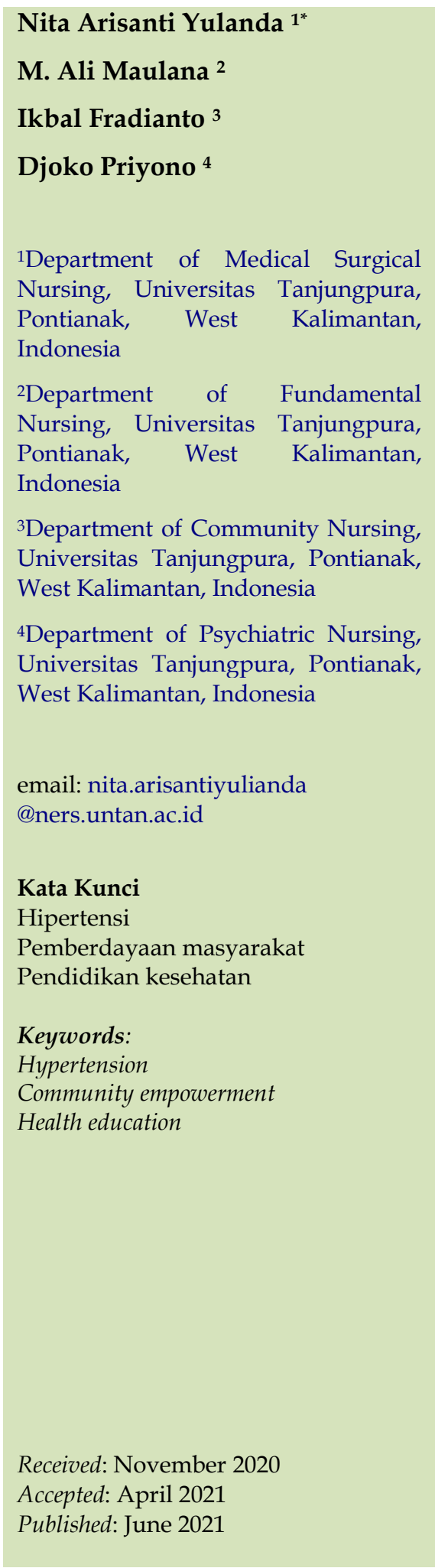

\begin{abstract}
Abstrak
Hipertensi merupakan penyakit tidak menular dengan angka kejadian yang semakin meningkat terutama pada lansia. Salah satu penyebabnya adalah banyak penderita yang tidak rutin bahkan tidak minum obat setelah mengalami hipertensi. Selain pengobatan, faktor diet juga dapat meningkatkan risiko kenaikan tekanan darah. Pengabdian masyarakat diharapkan mampu membantu masalah kesehatan secara mandiri. Pemberdayaan masyarakat dilakukan melalui tahap Pengenalan kondisi wilayah, Survey mawas diri, Musyawarah, Perencanaan partisipatif, Pelaksanaan Kegiatan, dan Pembinaan Kelestarian. Pelaksanaan dilakukan dengan pemberian pendidikan kesehatan tentang diet hipertensi dan kepatuhan pengobatan dengan menggunakan media poster berjudul "CAT HITAM" saat pandemi, sebelum dan setelah kegiatan dilakukan pretest-posttest untuk mengetahui pengetahuan diet dan kepatuhan pengobatan penderita hipertensi, Pendidikan Kesehatan mengenai kegiatan yang bisa dilakukan, konsumsi makanan yang disarankan, dan kepatuhan pengobatan yang harus dipatuhi oleh penderita hipertensi saat pandemi. Hasil pretest-postest menunjukkan perbedaan pengetahuan diet dan pengobatan sebelum dan setelah dilakukan pendidikan kesehatan dengan $\mathrm{p}$ value $<0,05$. Masalah diet dari hasil pengkajian masyarakat sebagian besar mengenai batas konsumsi garam bagi hipertensi dan pengobatan. Sebagian besar responden mengatakan menghentikan pengobatan dikarenakan merasa sudah tidak memiliki keluhan. Perlu kerjasama dari berbagai pihak selalu memotivasi lansia mengikuti aturan diet dan pengobatan hipertensi.
\end{abstract}

\begin{abstract}
Hypertension is a non-communicable disease with an increasing incidence, especially in the elderly. One of the reasons is that many sufferers do not routinely even take medication after experiencing hypertension. In addition to medication, dietary factors can also increase the risk of an increase in blood pressure. Community service is expected to be able to help health problems independently. Community empowerment is carried out by introducing regional conditions, introspective surveys, deliberation, participatory planning, implementation of activities, and sustainability development. The implementation is carried out by providing health education about hypertension diet and medication adherence by using poster media entitled "CAT HITAM" during a pandemic, before and after the activity, pretest-posttest is carried out to determine dietary knowledge and medication adherence for hypertension sufferers, Health Education regarding activities that can be done, recommended food consumption, and medication adherence that hypertension sufferers must adhere to during a pandemic. The pretest-posttest results showed differences in knowledge of diet and medication before and after health education with a p-value $<0.05$. Dietary problems from the results of community assessments are mostly about the limits of salt consumption for hypertension and treatment. Most of the respondents said they stopped treatment because they felt they had no complaints. It needs cooperation from various parties to continuously motivate the elderly to follow the rules of diet and treatment of hypertension.
\end{abstract}




\section{PENDAHULUAN}

Perubahan transisi epidemiologi dalam masalah kesehatan sedang dihadapi Indonesia saat ini, penyakit tidak menular (PTM) cenderung mengalami peningkatan, sedangkan penyakit menular belum teratasi sepenuhnya. PTM menjadi isu penting karena perlunya dukungan dalam pencegahan dan pengendalian PTM serta faktor risikonya dalam upaya mendorong perubahan perilaku masyarakat untuk hidup sehat (Pradono et al., 2005). Data World Health Organization (WHO) menyebutkan bahwa persentase kematian akibat PTM sebesar 63\% dibandingkan dengan penyakit menular (Putri et al., 2019). Prosentase angka kematian penyakit tidak menular di Indonesia mengalami peningkatan dari tahun 1990 sebesar 37\% meningkat menjadi 57\% di tahun 2015

Salah satu PTM yang beresiko di tengah pandemi COVID-19 ini adalah hipertensi (Susanti et al., 2021). Menurut WHO (2013), apabila tekanan darah seseorang kurang dari $120 \mathrm{mmHg}$ untuk tekanan sistolik dan kurang dari $80 \mathrm{mmHg}$ untuk tekanan darah diastolik menunjukkan tekanan darah dalam batas normal. Seseorang yang dikatakan hipertensi bila tekanan darah sistolik lebih dari $140 \mathrm{mmHg}$ dan tekanan diastolik lebih dari $90 \mathrm{mmHg}$.

Hasil Riset Kesehatan Dasar (RISKESDAS) tahun 2018 menggambarkan prevalensi Hipertensi dari hasil pengukuran penduduk dengan jenis kelamin laki-laki $31,3 \%$ dan perempuan $36,9 \%$. Dengan prevalensi usia penderita hipertensi 55 - 64 tahun sebesar $55,2 \%$, usia 65 - 74 Tahun sebesar 63,2\% dan lebih dari 75 tahun sebesar $69,5 \%$. Hasil pendataan proporsi riwayat minum obat masih ada $32,3 \%$ yang tidak rutin minum obat dan $13,3 \%$ tidak minum obat. Kondisi ini dikarenakan merasa sudah sehat $(59,8 \%)$ dan ada yang tidak rutin ke fasilitas layanan kesehatan $(31,3 \%)$ serta masih ada beberapa alasan yang membuat penderita hipertensi tidak mengkonsumsi obat hipertensi (Kementerian Kesehatan Republik Indonesia, 2018)

Berbagai upaya telah dilakukan oleh pemerintah dalam penanggulangan penyakit tidak menular yang salah satunya hipertensi. Sasaran pencegahan penyakit hipertensi secara operasional dilakukan pada beberapa tatanan area (Rumah tangga, tempat kerja, tempat pelayanan kesehatan, tempat sekolah, tempat umum, dil). Strategi promosi dan pencegahan secara umum meliputi Advokasi, Bina suasana dan pemberdayaan masyarakat. Peningkatan bina suasana melalui kemitraan pemberdayaan masyarakat dengan melibatkan masyarakat secara aktif dalam proses pemecahan masalah kesehatan yang dihadapi akan meningkatkan kemampuan masyarakat dan lingkungannya dalam pencegahan dan penanggulangan penyakit secara mandiri (Kementerian Kesehatan Republik Indonesia, 2011).

Pemberdayaan masyarakat merupakan salah satu upaya meningkatkan kesadaran dan kemampuan masyarakat untuk mengenal, mengatasi, memelihara, melindungi serta meningkatkan kesejahteraan secara mandiri. Sedangkan pemberdayaan masyarakat dibidang kesehatan ialah upaya menumbuhkan kesadaran, keinginan dan kemampuan memelihara dan meningkatkan status kesehatan masyarakat secara mandiri (Supardan, 2013). Pemberdayaan masyarakat dalam bidang kesehatan sesuai dengan Undang undang Republik Indonesia, nomor 36 tahun 2009 tentang kesehatan, bahwa pembangunan kesehatan harus ditujukan untuk meningkatkan kesadaran, kemauan, dan kemampuan hidup masyarakat yang setinggi-tingginya, sebagai investasi bagi pembangunan sumber daya masyarakat. Mewujudkan, mempertahankan dan meningkatkan derajat kesehatan masyarakat merupakan kewajiban setiap orang yang 
menjadi tanggungjawab pemerintah untuk memotivasi dan memberdayakan peran aktif masyarakat.

Kegiatan pengabdian masyarakat yang dilakukan kali ini berusaha meningkatkan pemberdayaan masyarakat dengan hipertensi. Kegiatan ini diharapkan mampu meningkatkan kesadaran masyarakat dengan hipertensi dalam mempertahankan kesehatannya. Hal ini dikarenakan hipertensi merupakan faktor risiko terjadinya penyakit jantung koroner, stroke, dan penyakit ginjal. Modifikasi gaya hidup sebagai salah satu terapi penting yang direkomendasikan oleh seventh report of the joint national committee on prevention, detection, evaluation and treatment of high blood pressure (INC 7). Modifikasi gaya hidup salah satunya adalah modifikasi asupan makanan sehari-hari yang memiliki peranan dalam pencegahan kenaikan tekanan darah pada penderita hipertensi (Kumala, 2014)

Pengontrolan tekanan darah dan pencegahan komplikasi salah satunya dipengaruhi oleh faktor pengetahuan dan pola makan. Penelitian Firmawati et al. (2015) menyampaikan hasil penelitian sebanyak 60,4\% penderita hipertensi memiliki perilaku yang kurang baik pada diet hipertensi, sehingga perlunya dilakukan upaya memperbaiki perilaku yang kurang baik pada penderita hipertensi. Sebagai salah satu upaya untuk mengatasi perilaku yang kurang baik pada masyarakat dengan hipertensi, maka tim PKM Jurusan Keperawatan berupaya melakukan pemberdayaan masyarakat dalam mengatasi kesehatannya. Pemberdayaan masyarakat di bidang kesehatan, menurut Kementerian Kesehatan Republik Indonesia (2019) menyatakan ada 6 tahapan yang harus dilalui, diantaranya:

1. Pengenalan Kondisi Wilayah

2. Survey mawas diri

3. Musyawarah

4. Perencanaan partisipatif

5. Pelaksanaan Kegiatan

\section{Pembinaan Kelestarian.}

Tahapan kegiatan ini dilakukan tim pengabdian masyarakat jurusan keperawatan Universitas Tanjungpura dan petugas Puskesmas Perumnas 1 Kota Pontianak sebagai usaha membantu upaya pemerintah dalam memberikan edukasi dalam rangka meningkatkan pengetahuan diet dan pengobatan pada masyarakat dengan hipertensi.

\section{METODOLOGI}

Pelaksanaan kegiatan pengabdian masyarakat di wilayah kerja Puskesmas Perumnas 1 Kota Pontianak yang dilaksanakan melalui 6 tahapan:

1. Tahap 1: Pengenalan Kondisi Lapangan. Kegiatan yang dilakukan pada tahap ini Tim PKM akan melakukan orietasi lapangan dengan koordinasi dengan pihak Puskesmas Perumnas 1 Kota Pontianak. Kegiatan yang dilakukan adalah mengetahui identitas penderita hipertensi meliputi nama, usia dan alamat tempat tinggal penderita hipertensi di wilayah kerja Puskesmas Perumnas 1. Diharapkan pengabdian dapat tepat sasaran pada penderita hipertensi;

2. Tahap 2: Survey Mawas Diri, kegiatan yang dilakukan berupa dengan koordinasi dengan pihak Puskesmas Tim PKM yaitu menentukan prioritas sasaran PKM. Kegiatan ini memprioritaskan pada lansia dengan hipertensi;

3. Tahap 3: Musyawarah. Pada tahap ini musyawarah yang dilakukan dengan pihak puskesmas dikarenakan kondisi masa pandemic Covid-19. Musyawarah yang dibahas mengenai perijinan sasaran PKM, kegiatan yang akan dilakukan dan kontribusi yang diberikan pada penderita hipertensi;

4. Tahap 4: Perencanaan partisipasif, melakukan diskusi kembali hasil musyawarah dengan pihak Puskesmas, kemudian membentuk tim pengabdian 
untuk melakukan kunjungan rumah, selain itu juga menyusun strategi pelaksanaan kegiatan saat kunjungan rumah, menyiapkan sarana prasarana yang diperlukan selama kunjungan, kebutuhan anggaran kegiatan, jadwal pelaksanaan kunjungan, pembagian tugas serta sosialisasi materi pada masing-masing tim;

5. Tahap 5: Pelaksanaan Kegiatan. Pada tahap ini akan dilakukan kunjungan rumah ke masing - masing lansia dengan hipertensi dengan membawa kuesioner, materi penyuluhan dan bingkisan untuk lansia hipertensi;

6. Tahap 6: Pembinaan Kelestarian, pada tahap 6 akan dilakukan koordinasi dengan pihak Puskesmas dan kader posyandu lansia agar pemberian edukasi pada penderita hipertensi dapat berkelanjutan.

\section{HASIL DAN PEMBAHASAN}

Pelaksanaan kegiatan PKMDosen Jurusan Keperawatan dilaksanakan sesuai dengan tahapan pemberdayaan masyarakat dibidang kesehatan dimulai dari Tahap 1 atau Kegiatan orientasi lapangan untuk mengenal kondisi lapangan dilaksanakan pada tanggal 10 Agustus 2020. Kegiatan pada tahap ini berkunjung ke Puskesmas Perumnas 1 di Jl. M Yusuf Sungai Jawi Luar Kecamatan Pontianak Barat. Kegiatan selanjutnya, melakukan koordinasi tentang rencana kegiatan yang akan dilakukan dengan pihak Puskesmas Perumnas 1 Pontianak Barat. Tim PKM menyampaikan Pelaksanaan kegiatan PKM yang dilakukan tidak mengumpulkan warga, namun dengan melakukan kunjungan rumah dengan memperhatikan protocol kesehatan, setelah mendapatkan persetujuan dari Puskesmas kemudian melakukan Tahap 2 yaitu survey mawas diri dengan mengidentifikasi penderita hipertensi yang sesuai dengan prioritas sasaran pengabdian yang akan dilaksanakan yaitu 30 lansia dengan hipertensi.
Kegiatan selanjutnya Tahap 3 Musyawarah dengan Kepala Puskesmas dan kader posyandu lansia mengenai pemberian edukasi dengan menggunakan poster penyuluhan dengan judul "CAT HITAM" Saat Pandemi. Judul "CAT HITAM" diartikan "Cara Tangani Hipertensi Dengan Tepat Untuk Masyarakat". Poster yang digunakan berisi hal - hal yang sebaiknya dilakukan oleh penderita hipertensi selama pandemi Covid-19, dan menu diet yang tepat untuk penderita hipertensi. Selain memberikan edukasi dengan menggunakan poster, juga akan diberikan bingkisan bahan makanan sebagai contoh makanan yang disarankan untuk penderita hipertensi dan menjelaskan manfaat dari bahan makanan yang diberikan.

Pelaksanaan Kegiatan Tahap 4. Perencanaan partisipasif yang dilaksanakan pada tanggal 13 Oktober 2020, yaitu membagi tim PKM menjadi 3 tim yang masing - masing tim terdiri dari 2 orang yang akan mengunjungi 10 penderita hipertensi, tim akan melakukan edukasi sesuai isi poster diantaranya mengenai rajin berolahraga terutama pada pagi hari dan istirahat yang cukup minimal 8 jam/hari, mengajarkan cara cuci tangan menggunakan sabun, tetap menjaga kebersihan lingkungan, tidak merokok atau menghindari asap rokok, apabila demam dan sesak segera ke pelayanan kesehatan terdekat, menggunakan masker saat keluar rumah, menjaga jarak dan selalu berdo'a. Materi pendidikan kesehatan pengetahuan diet hipertensi mengenai makanan dengan gizi seimbang bagi hipertensi yaitu mengurangi konsumsi garam, cukup buah dan sayur, hindari makanan yang diawetkan dan berminyak, minum cukup air dan konsumsi makanan yang dimasak sempurna. Sedangkan Pendidikan kesehatan untuk kepatuhan pengobatan, disarankan agar pasien hipertensi minum obat secara rutin, selalu membawa obat saat bepergian dan tidak berhenti minum walaupun badan merasa sudah sehat. 
Tahap 5 Pelaksanaan kegiatan. Kegiatan dilaksanakan pada tanggal 14 Agustus 2020. Kegiatan yang dilakukan diawali dengan pembukaan bersama Kepala Puskesmas Perumnas 1 Ibu Martiningsih SKM, dilanjutkan dengan melakukan kunjungan rumah bagi penderita hipertensi di wilayah kerja Puskesmas Perumnas 1 Kota Pontianak. Kegiatan yang dilakukan selama kunjungan rumah adalah melakukan identifikasi data umum, kuesioner pengetahuan diet dan kuesioner kepatuhan pengobatan hipertensi (Morisky Medication Adherence Scale-8) yang dibacakan oleh Tim PKM, kegiatan selanjutnya memberikan penyuluhan dengan menggunakan poster penyuluhan dengan judul "CAT HITAM" saat pandemi, kemudian melakuan postest dengan kuesioner yang sama. Sebelum mengakhiri kunjungan tim memberikan bingkisan bahan makanan sebagai contoh makanan yang disarankan untuk penderita hipertensi dan menjelaskan manfaat dari bahan makanan yang diberikan.

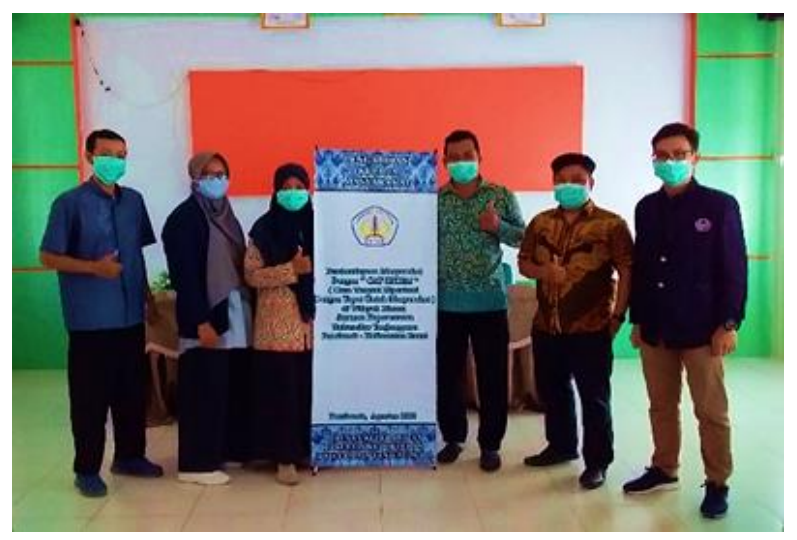

Gambar 1. Kegiatan pengabdian kepada masyarakat Jurusan Keperawatan Universitas Tanjungpura

Kegiatan Tahap 6, adalah mengunjungi kader posyandu lansia untuk koordinasi agar kegiatan edukasi pada penderita hipertensi tetap berlangsung dengan cara menempel poster pengabdian "CAT HITAM" saat Pandemi di dinding posyandu lansia, mengingatkan warga untuk tetap beraktivitas selama di rumah dan menjaga kesehatan penderita hipertensi melalui pengeras suara posyandu.

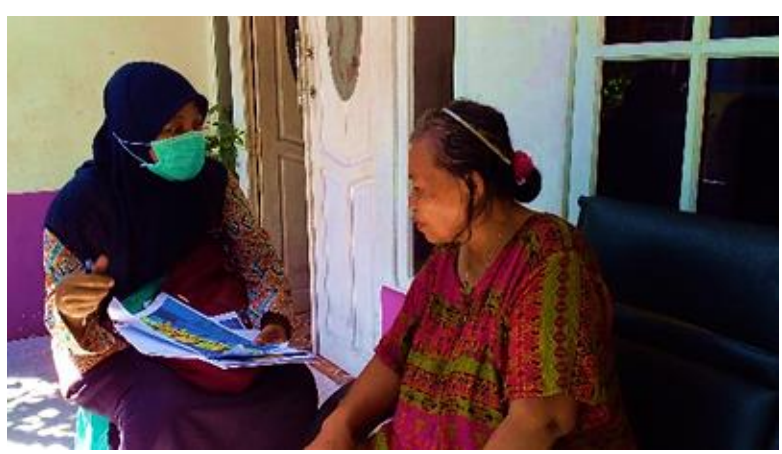

Gambar 2. Kegiatan Penyuluhan Hipertensi dengan Poster "CAT HITAM" Saat Pandemi

Berdasarkan hasil pengkajian data demografi didapatkan data penderita hipertensi di wilayah kerja Puskemas Perumnas 1 Kota Pontianak sebagian besar penderita hipertensi berjenis kelamin perempuan (60\%), berusia 55 - 64 (43,3\%), tingkat Pendidikan sebagian besar SMP (43,3\%), pekerjaan ibu rumah tangga (63,3\%), lama sakit lebih dari 5 tahun (70\%) dan memiliki dukungan keluarga baik (60\%).

Pernyataan ini sesuai dengan yang disampaikan Anggraini (2012) pada usia 45-55 tahun wanita mengalami perubahan kuantitas hormon esterogen yang memiliki fungsi melindungi pembuluh darah dari kerusakan, terutama ketika usia lebih dari 65 tahun risiko hipertensi akan semakin tinggi karena faktor hormonal. Selain karena faktor hormonal, Menurut Aryzki dan Akrom (2018), sebagian besar berusia lebih dari 50 tahun elastisitas pembuluh darah arteri akan hilang sehingga mengakibatkan adanya perubahan struktural dan fungsional pada sistem pembuluh darah. Semakin bertambah usia seseorang akan semakin meningkatkan risiko hipertensi. Sehingga perlunya meningkatkan pengetahuan tentang diet dan mengontrol makanan yang dikonsumsi agar tekanan darah tetap stabil serta pentingnya dukungan keluarga dalam pengelolaan diet hipertensi.

Hasil pretest menggunakan kuesioner tentang pengetahuan diet dan kepatuhan pengobatan hipertensi terdapat 12 penderita hipertensi dengan nilai dibawah 
rerata, hal ini menunjukkan masih terdapat penderita hipertensi yang belum paham tentang pengetahuan diet dan kepatuhan pengobatan hipertensi. Nilai kuesioner yang rendah terutama mengenai konsumsi makanan asin, makanan gorengan dan sebagian besar tidak membawa obat saat berpergian serta mengurangi atau berhenti minum obat hipertensi tanpa memberitahu dokter yang masih dilakukan oleh penderita hipertensi dengan argumentasi sudah tidak memiliki keluhan. Sedangkan hasil postest pengetahuan diet dan kepatuhan pengobatan masih terdapat 8 responden dengan nilai dibawah rerata. Sedangkan untuk hasil analisa uji paired $t$ test didapatkan $p$-value $<0,05$ yang diartikan terdapat perbedaan nilai antara pretest dan posttest.

Pengabdian masyarakat yang serupa dilakukan oleh Muhlishoh dan Nurzihan (2020) melalui kegiatan konseling dengan media leaflet yang dilakukan mampu merubah perilaku makan terutama mengenai konsumsi garam (Natrium). Sehingga perlunya pelaksanaan konseling secara rutin agar penderita hipertensi menunjukkan perilaku makan yang benar dan bisa melestarikan perilaku tersebut dalam kehidupan sehari hari. Penelitian yang dilakukan Suyoto et al. (2019) menyatakan hasil pretest sebanyak $72 \%$ responden kurang patuh terhadap diet hipertensi sebelum diberikan intervensi manajemen hipertensi dan setelah dilakukan intervensi edukasi dengan aplikasi patuh menunjukkan $74 \%$ responden menjadi patuh melakukan diet hipertensi. Pasien hipertensi yang tidak menjaga makanan yang sesuai diet hipertensi dan kepatuhan pengobatan yang berkelanjutan untuk mengontrol hipertensi akan berisiko terhadap kenaikan tekanan darah.

Data hasil RISKESDAS (2018) juga menunjukkan alasan tidak rutin minum obat pada penduduk hipertensi lebih dari setengah $(59,8 \%)$ dikarenakan merasa sudah sehat.
Kepatuhan pengobatan menjadi faktor penting dalam pengontrolan tekanan darah pada pasien hipertensi, dan menjadi salah satu syarat untuk mendapatkan efektivitas terapi dan meningkatkan kualitas hidup pasien hipertensi (Gwadry-Sridhar et al., 2013)

Peningkatan tekanan darah pada penderita hipertensi dipengaruhi oleh berbagai faktor diantaranya adalah pengetahuan, sikap dan dukungan keluarga. Selain pengetahuan mengenai diet, penderita hipertensi juga harus tahu tentang pengobatan hipertensi agar mampu mengontrol tekanan darah tidak meningkat. Perawat dengan salah satu peran sebagai konselor dan edukator diharapkan mampu memberikan solusi, informasi tentang perawatan dan pengobatan pasien. Sehingga dalam kegiatan pengabdian masyarakat dengan pemberdayaan masyarakat penderita hipertensi mampu meningkatkan pengetahuan, sikap dan perilaku dalam mengendalikan penyakit hipertensinya. Agar kegiatan ini dapat berkelanjutan diperlukan adanya dukungan selain dari keluarga, dari kader Kesehatan, tokoh masyarakat dan petugas Kesehatan terdekat, sehingga semua pihak dapat berpartisipasi dan mendukung upaya pengendalian hipertensi.

\section{KESIMPULAN}

Pemberdayaan Masyarakat dibidang kesehatan merupakan salah satu upaya yang bisa dilakukan untuk memandirikan masyarakat dalam mengelola penyakitnya terutama penyakit yang tidak menular, kegiatan pemberdayaan masyarakat dilakukan sebanyak 6 tahap dengan melibatkan partisipasi tenaga kesehatan, kader, dan serta tokoh masyarakat. Selain mampu meningkatkan pengetahuan pemberdayaan masyarakat juga mampu merubah perilaku kesehatan menjadi semakin lebih baik. Sehingga disarankan perlunya keterlibatan aktif masyarakat dalam upaya peningkatan kegiatan pemberdayaan masyarakat di 
berbagai wilayah kerja Puskemas agar kesehatan masyarakat Indonesia.

\section{UCAPAN TERIMA KASIH}

Pemberdayaan Masyarakat melalui kegiatan pengabdian kepada masyarakat dapat dilaksanakan dengan baik berkat adanya kerjasama dan dukungan dari segala pihak, penulis mengucapkan terimakasih pada Dana DIPA Universitas Tanjungpura Tahun 2020, Lembaga Penelitian dan Pengabdian Kepada Masyarakat (LPPKM) Universitas Tanjungpura Pontianak, Kepala Puskesmas Perumnas 1 Pontianak Barat beserta jajarannya atas kerjasama selama pelaksanaan Pengabdian Kepada Masyarakat, Mahasiswa angkatan 2018 dan 2019 Jurusan Keperawatan yang telah ikut serta membantu dalam kelancaran Pengabdian Kepada Masyarakat ini dan masyarakat Desa Sungai Jawi yang telah aktif selama pelaksanaan kegiatan Pengabdian Kepada Masyarakat.

\section{REFERENSI}

Anggraini. 2012. Jenis Kelamin Penderita Hipertensi. Bandung: Remaja Rosida Karya

Aryzki, S., Akrom, A. 2018. Pengaruh Brief Counseling Terhadap Konsumsi Lemak Pada Pasien Hipertensi di RSUD dr. H. Moch Ansari Saleh Banjarmasin. JSFK (Jurnal Sains Farmasi \& Klinis). $\quad$ 5(1):33-40. https://doi.org/10.25077/jsfk.5.1.33-40.2018

Firmawati, E., Rasyida, Z.M., Santosa, T. 2015. Pengaruh Blog Edukatif Tentang Hipertensi Terhadap Pengetahuan Tentang Hipertensi dan Perilaku Diet Hipertensi pada Pasien Hipertensi di Wilayah Kerja Puskesmas Wirobrajan Yogyakarta. IJNP (Indonesian Journal of Nursing Practices). 1(2):99-108. https://doi.org/10.18196/ijnp.v1i2.649

Gwadry-Sridhar, F.H., Manias, E., Lal, L., Salas, M., Hughes, D.A., Ratzki-Leewing, A., Grubisic, M. 2013. Impact of interventions on medication adherence and blood pressure control in patients with essential hypertension: a systematic review by the ISPOR medication adherence and persistence special interest group. Value Health. 16(5):863-871. https://doi.org/10.1016/j.jval.2013.03.1631

Kementerian Kesehatan Republik Indonesia. 2019. Buku Saku Tahapan Pemberdayaan Masyarakat Bidang Kesehatan Bagi Kader. Jakarta: Direktorat Promosi Kesehatan dan Pemberdayaan Masyarakat Kementerian Kesehatan Republik Indonesia.

Kementerian Kesehatan Republik Indonesia. 2018. Hasil Utama RISKESDAS 2018. Jakarta: Badan Penelitian dan Pengembangan Kesehatan Kementerian Kesehatan Republik Indonesia.

Kementerian Kesehatan Republik Indonesia. 2011. Promosi Kesehatan Di Daerah Bermasalah Kesehatan. Jakarta: Pusat Promosi Kesehatan Kementerian Kesehatan Republik Indonesia.

Kumala, M. 2014. Peran Diet Dalam Pencegahan Dan Terapi Hipertensi. Damianus Journal of Medicine. 13(1):50-61.

Muhlishoh, A., Nurzihan, N.C. 2020. Upaya Perubahan Perilaku Makan Pada Penderita Hipertensi Melalui Konseling Gizi di Wilayah Puskesmas Gambirsari, Surakarta. Jurnal Pengabdian Kepada Masyarakat Ungu (ABDI KE UNGU). 2(2):77-81.

Pradono, J., Senewe F., Kristanti, C.M., Soemantri, S. 2005. Transisi kesehatan di indonesia (kajian data surkesnas). Jurnal Ekologi Kesehatan. 4(3):336350 .

Putri, N.G., Herawati, Y.T., Ramani, A. 2019. Peramalan Jumlah Kasus Penyakit Hipertensi Di Kabupaten Jember Dengan Metode Time Series. Journal of Health Science and Prevention. 3(1):39-46. https://doi.org/10.29080/jhsp.v3i1.161

Supardan, I., 2013. Pemberdayaan Masyarakat Bidang Kesehatan. Bandung: Bumi Aksara

Susanti, Y., Anita, A., Santoso, D.Y.A. 2021. Perilaku Cerdik Penderita Hipertensi Dimasa Pandemi Covid 19. Jurnal Keperawatan. 13(1):61-76. https://doi.org/10.32583/keperawatan.v13i1 .1116 
Suyoto, S., Agushybana, F., Suryoputro, A. 2020. Pengaruh Penggunaan Aplikasi Patuh Terhadap Kepatuhan Melakukan Diet Hipertensi pada Pasien Hipertensi di Kabupaten Wonosobo. Jurnal Penelitian dan Pengabdian kepada Masyarakat UNSIQ. 7(1):3137. https://doi.org/10.32699/ppkm.v7i1.956

World Health Organization. 2013. Global Health Observatory (GHO) Raised Blood Pressure Situation and Trends. https://www.who.int/gho/publications/w orld_health_statistics/EN_WHS2013_Full.pdf 